\title{
Science, Technology, Engineering, and Mathematics Education for Industry 4.0 in Technical and Vocational High Schools: Investigation of Teacher Professional Development
}

\author{
Devrim Akgunduz*, Canan Mesutoglu \\ Science, Technology, Engineering, and Mathematics Education Research Center, Istanbul Aydin University, Istanbul, Turkey \\ *Corresponding author: devrimakgunduz@aydin.edu.tr
}

\section{ABSTRACT}

The goals of this study were to investigate technical and vocational education (TVET) teachers' progress in their knowledge, perceptions, and competencies related to Industry 4.0 components and Science, Technology, Engineering, and Mathematics (STEM) within the context of a professional development program. A case study design was followed to reveal in-depth information on teacher improvement. Data sources included the Teacher Knowledge Survey, Teacher Perceptions Survey, and Industry 4.0 and STEM Competencies Survey. Results indicated significant improvement in teachers' Industry 4.0 competencies and their content knowledge of Industry 4.0 components and STEM. Teachers reported a culture of collaboration in their school, increased teacher and student motivation, and positive attitudes toward TVET with implementation of the STEM PD program. The results point to the need to help teachers in designing certain aspects of STEM lesson plans including the integration of mobile programming, robotic programming and virtual reality meaningfully into the lesson content. Further implications for research and practice are presented in light of the findings.

KEYWORDS: industry 4.0; science education; science, technology, engineering, and mathematics education; teacher professional development; vocational and technical education

\section{INTRODUCTION}

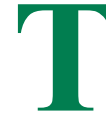

The economical and societal changes and the emerging characteristics of new occupations correlate with technical and vocational education and training (TVET) practices (Choi et al., 2019; Nilsson, 2010). Envisioning the Future of Education and Jobs report (Schleicher et al., 2019) predicted that Industry 4.0 together with the advances in information technologies were creating new professional domains while persistently changing how jobs were defined.

Originating in Germany, Industry 4.0 refers to the fourth industrial revolution that emerged following the developments in information and communications technologies (Gilchrist, 2016; Rojko, 2017). Industry 4.0 includes the concepts: Industry 4.0 tools (e.g., virtual reality, 3D printing), internet of things, examples such as smart factories, and virtualization of the real world (Rojko, 2017). The emergence of Industry 4.0 is leading to more interdisciplinary work in teaching and development of educational knowledge and practices (Chou et al., 2018). This underlines the critical importance of Science, Technology, Engineering, and Mathematics (STEM) education with its focus on an interdisciplinary approach and using new technologies in educational practices.

To arrive at sustained economic growth worldwide, advancing in technology and innovation capacity, encouraging productivity, creativity, and entrepreneurship have been identified as essential steps (International Labour Organization, 2019). K-12 students should be actively engaged in scientific and engineering practices, building on their knowledge in different disciplines while involved in a systematic process of design (Bybee, 2018; NRC, 2012). In line with these demands, TVET focuses more on STEM education in recent years (Dougherty and Macdonald, 2020). TVET should help students acquire skills associated with the workforce needs of rapidly changing societies (Fletcher and Gordon, 2017; Hoeckel and Schwartz, 2010; Tripney and Hombrados, 2013). Comprising technological and physical infrastructure, variety of career clusters and integration of disciplines that naturally take place (Blosveren and Voytek, 2015; Reeve, 2016), technical and vocational high schools provide a convenient learning environment for raising STEM skilled learners. For the rise of a generation of STEM innovators, one essential component is providing professional development (PD) opportunities to teachers continuously (Capraro et al., 2016; Chai, 2019). Although teachers are interested in learning about integrated STEM, research has noted teachers' unpreparedness to implement STEM approaches in the classroom (Shernoff et al., 2017). This study investigated the impacts of a longterm teacher PD program on TVET high school teachers' knowledge, perceptions, and competencies related to Industry 4.0 and STEM education. 


\section{Theoretical Background}

\section{STEM education}

The $21^{\text {st }}$ century requires individuals to work collaboratively on local and global problems (NRC, 2012). STEM education highlights the integration of multiple disciplines in the context of real-world issues (The National Academy of Sciences, 2014). Moore et al. (2014) defined integrated STEM education as "an effort to combine some or all of the four disciplines of STEM into one class, unit, or lesson that is based on connections between the subjects and real-world problems" (p. 38).

STEM education has merit in equipping students with engineering habits of mind, helping students produce multiple innovative solutions to $21^{\text {st }}$-century problems, think creatively, and systematically (Akgunduz, 2018; Bybee, 2018; Corlu et al., 2014; Johnson et al., 2015, NRC, 2014). STEM education contributes to the development of students' problem-solving skills, abilities to engage in evidence-based explanations (Bybee, 2018), innovation capacities, collaboration, critical thinking (Martín-Páez et al., 2019, NRC, 2012), and interest towards STEM and STEM careers (Akgunduz, 2016; Baran et al., 2019; Martín-Páez et al., 2019; Shahali et al., 2017).

Future generation of workers will require competency in communication, collaboration, skills for digital transformation, solving complex problems, and leadership (Akgunduz, 2016; Akgunduz and Mesutoglu, 2020; OECD, 2019). Successful transition to work-life necessitates students' familiarity with STEM disciplines and Industry 4.0 components (e.g., the internet of things, smart factories, and cyber-physical systems) (Lasi et al., 2014; OECD, 2019; Schleicher et al., 2019). For students to be equipped with the knowledge and skills demanded by the labor force, an important enabler is a strong collaboration between schools and industries (Ayonmike and Okeke, 2017; Fletcher and Tyson, 2017; Watters and Christensen, 2014). TVET is promising with its continuous interaction with the labor market and industries to raise competitive young people prepared for work-life (Nilsson, 2010). For the successful implementation of STEM education, stakeholders to share a co-constructed vision of STEM are an outstanding factor (Holmlund et al., 2018). TVET presents a promising context towards a shared STEM education vision with the naturally occurring collaborations with the industry.

\section{STEM education for TVET and training}

UNESCO (2004) defined TVET as “...those aspects of the educational process involving, in addition to general education, the study of technologies and related sciences and the acquisition of practical skills, attitudes, understanding, and knowledge relating to occupation in various sectors of economic life" (p. 7). Given the fact that vocational education, technical education, career-vocational technical education, TVET are used interchangeably, this study adopted and used 'TVET and training' (Gordon, 2008; Tripney and Hombrados, 2013).

The rapidly changing global demands of the $21^{\text {st }}$ century draw increasing attention to STEM education practices and related funding needs within the context of TVET (Wilkin and Welty, 2014). According to the recent employment growth and productivity trends, job creation efforts fall short of the demands of the expanding growth of the labor force (International Labour Organization, 2019). The role of TVET should be prioritized to support innovative individuals in the society who can produce solutions for cultivating the economy (Castellano et al., 2003). STEM education leads to improvement in TVET students in academic achievement, self-efficacy, and interest toward STEM careers (Akgunduz and Mesutoglu, 2020; Chang et al., 2015; Dougherty and Macdonald, 2020; Oran et al., 2018; Reeve, 2016; Wu et al., 2019). TVET is a critical contributor to students' acquirement of skills valuable for successful employment (Jou et al., 2014; OECD, 2009).

A rich learning environment is part of successful STEM education which can be attained through the physical and technical infrastructure of TVET (Reeve, 2006; Wilkin and Welty, 2014). The use of mathematics, science, and technology content in technical branches (e.g., industrial automation, mechatronics) of TVET create an ideal context for STEM education (Dixon and Hutton, 2016). Vocational and technical education should embrace the vision of innovation, meaningful application of knowledge of multiple disciplines and should prioritize collaboration with the industry and education politicians to equip students with the necessary skills to meet the demands of the workforce (Watters and Christensen, 2014).

\section{Purpose of the study}

TVET high school students need support on developing high order thinking skills such as creative thinking, reasoning, problem-solving, and abstract thinking (Uzmanoglu et al., 2010; Watters and Christensen, 2014). For students to acquire these skills as they work on 21st-century problems, one critical factor is to have competent teachers in STEM education who have positive perceptions toward STEM teaching (Corlu et al., 2014; OECD, 2015; Vennix et al., 2017). TVET should reform its educational practices to better adapt to the STEM education movement and contribute to students' $21^{\text {st }}$ century skills development (Fletcher and Gordon, 2017). Important enablers of accomplishing this goal are (a) PD programs to support teachers and to understand the challenges teachers face in implementing STEM education practices, and (b) collaborations between TVET, policymakers and the industry (Ayonmike and Okeke, 2017; Holmlund et al., 2018; Shernoff et al., 2017; Uzmanoglu et al., 2010). In overcoming the barrier of TVET teachers' limited competencies concerning the needs of the business world, educators should consider conducting scientific studies within the context of teacher PD programs (Hoekstra et al., 2018; Nadelson et al., 2013; Tripney and Hombrados, 2013).

This study addressed the need for STEM teacher development programs that are conceptually based on the demands of industry and the changing profile of occupations. The study investigated technical and vocational high school teachers' 
improvement as a result of participation in a year-long PD program. The research questions that guided the study were: (a) What are the differences in teachers' content knowledge and perceptions related to STEM education and Industry 4.0? and (b) to what extent did teachers' Industry 4.0 competencies improve?

\section{METHOD}

\section{Research Design}

The study followed a qualitative research design (Cohen et al., 2007) to investigate teachers' improvement. A case study approach was employed to be able to examine a contemporary phenomenon in its real-life context (Yin, 2008). Case studies lead to a rich exploration of the characteristics of a person, clique, class, or community under investigation (Cohen et al., 2007).

The study investigated the outcomes of a 1-year grant project "STEM Education for Industry 4.0: Technical and Vocational high schools," administered as a partnership between the Ministry of National Education of Turkey and the funder. An online application form was shared with the public through university networks, personal networks, and social media. Examination of applications resulted in the identification of four schools with a total of 39 teachers. The schools were selected based on five criteria: (a) School vision; whether the school administration declares an interest in the implementation of innovative teaching methods, (b) location of the school due to researcher convenience, (c) teaching staff; whether the school has teachers of basic sciences (e.g., biology, physics, mathematics) and technical branches (e.g., computer, electrical-electronics, industrial automation, machinery, mechatronics), (d) previous participation to projects, and (e) school's owning technical equipment (e.g., laboratories and coding materials) relevant to project tasks. Demographic information on teacher characteristics (e.g., gender and level of education) was collected at baseline using a web-based form. Table 1 illustrates participant teacher $(n=39)$ characteristics.

Out of the participant teachers from each school, one teacher was assigned as the STEM coordinator. Responsibilities of the STEM coordinator included the organization of two seminars

\begin{tabular}{ll}
\hline \multicolumn{2}{l}{ Table 1: Participant teacher demographics } \\
\hline Characteristics & Categories and percentages \\
\hline Gender & Male $(63.16 \%)$, Female $(36.84 \%)$ \\
Age & $40-49(36.84 \%), 30-39(34.21 \%), 50-59$ \\
& $(13.16 \%), 20-29(10.53 \%), 60$ and above $(5.26 \%)$ \\
Teaching field & Math (15.38\%), Computer (15.38\%), Biology \\
& $(12.82 \%)$, Physics (10.26\%), Machine (10.26\%), \\
& Electricity (10.26\%), Chemistry (7.69\%), \\
& Mechatronics (5.13\%), Electrical and electronics \\
& (5.13\%), Industrial automation $(2.56 \%)$, \\
& Electronics and communication (2.56\%), and \\
& Renewable energy (2.56\%) \\
Level of & Bachelor's degree (60.53\%), M.S. student (8\%), \\
education & M.S. degree (24\%), Ph.D. student (3\%), and \\
& Ph.D. degree (5.26\%) \\
\hline
\end{tabular}

on STEM education and Industry 4.0 for the school staff and students, the arrangement of regular meetings with the participant teachers for interaction and discussion, and followup on teachers on the project assignments (e.g., preparation of STEM lesson plans).

The first step was to receive confirmation from the Human Subjects Ethics Committee to proceed with data collection. Participation to the data collection was voluntary. All teachers signed individual Informed Consent Forms. In line with the case study approach, multiple forms of data were collected (Cohen et al., 2007; Creswell, 2012).

\section{Teacher PD Program}

The study focused on a year-long STEM teacher PD program implemented in four technical and vocational high schools. Table 2 outlines the program structure in the form of four distinct phases. The program was grounded on a blended learning approach (Akgunduz and Akinoglu, 2016, 2017; Castro, 2019; Siemens et al., 2015). The blended learning approach focuses combines traditional classroom instruction and practices of distance education, bringing together their strengths. Accordingly, the program was designed as a hybrid model, composing of faceto-face instruction, and online delivery (Siemens et al., 2015). As also outlined in Table 2, training on STEM, Industry 4.0, robotic programming, 3D printing, virtual reality, mobile programming, internet of things was delivered in the form of traditional classroom practices followed by online training.

As the teachers implemented the STEM lesson plans in the classroom,

students worked in groups. All teachers were provided with a technology kit for their lesson plan implementation during the mentoring phase.

\begin{tabular}{|c|c|c|}
\hline Phases & Duration & Activities \\
\hline $\begin{array}{l}\text { Phase } 1 \\
\text { Face-to-face } \\
\text { training }\end{array}$ & $60 \mathrm{~h}$ & $\begin{array}{l}\text { Engineering design modules, a combination } \\
\text { of; presentations, lectures, discussions, } \\
\text { workshop by IBM staff, training and } \\
\text { hands-on activities on STEM, Industry 4.0, } \\
\text { robotic programming, 3D printing, virtual } \\
\text { reality, mobile programming, internet of } \\
\text { things }\end{array}$ \\
\hline $\begin{array}{l}\text { Phase } 2 \\
\text { Online } \\
\text { training }\end{array}$ & $45 \mathrm{~h}$ & $\begin{array}{l}\text { Experts' (education and engineering faculty } \\
\text { members, IBM staff) presentations on Adobe } \\
\text { Connect on STEM education and Industry } \\
4.0 \text { components; robotic programming, } \\
\text { 3D printing, virtual reality, mobile } \\
\text { programming, cloud computing followed by } \\
\text { group discussions }\end{array}$ \\
\hline $\begin{array}{l}\text { Phase } 3 \\
\text { Monitoring }\end{array}$ & $\begin{array}{l}7 \text { months } \\
(45 \mathrm{~h})\end{array}$ & $\begin{array}{l}\text { Teacher groups' preparation and } \\
\text { implementation of four STEM lesson } \\
\text { plans, researchers' school visits and online } \\
\text { meetings on Adobe Connect to provide } \\
\text { feedback on lesson plans }\end{array}$ \\
\hline $\begin{array}{l}\text { Phase } 4 \\
\text { Project fair }\end{array}$ & $\begin{array}{l}\text { Single } \\
\text { day }\end{array}$ & $\begin{array}{l}\text { Keynote presentations, teacher, and student } \\
\text { groups' presentations to the public, the panel } \\
\text { with STEM coordinators }\end{array}$ \\
\hline
\end{tabular}


In the second phase, online training was designed according to the principals of distance education. Distance education stands as an alternative to face-to-face instruction where the participants interact in an online environment. The essential components of distance education include the share of information and data in a virtual platform, and active interaction where learning is monitored, and learners take on active tasks (Simonson et al., 2014). The PD program used a synchronous model where the teachers and the instructors interacted using Adobe Connect.

\section{Data Collection}

Levels descriptions for teacher content knowledge and the final list of codes representing teacher perceptions were finalized following joint discussions of the two researchers. Researchers proceeded with data analysis only after a sufficient level of agreement on the categories and codes. The internal consistency of the Industry 4.0 and STEM Competencies Survey was calculated using teacher responses during the pretest at the beginning of the project.

All data collection instruments were developed by the researchers whose backgrounds in STEM education can be proposed by their experience in the design of long-term teacher PD programs, delivery of courses to teacher candidates, taking part in STEM projects, and active role in university STEM centers. All data collection tools were finalized through expert reviews, followed by several discussions and revisions of the researchers.

\section{Teacher knowledge survey}

The survey consisted of six open-ended questions on Industry 4.0 and its components and on STEM education. Example survey questions used were: "How would you define: (a) STEM education? and (b) Industry 4.0?," "What is interdisciplinary learning to you?," and "Please write a short essay explaining the role and importance of STEM education and industry 4.0 for TVET." These questions facilitated the investigation of teachers' content knowledge on STEM and Industry 4.0.

\section{Teacher perception survey}

The survey contained seven open-ended questions focusing on teacher's perceptions towards STEM, STEM education, and Industry 4.0., Table 3. The seven open-ended questions were asked to facilitate teachers' reflection on their perceptions considering multiple aspects of the teacher PD program. Many of the questions also included probes to further catalyze teachers' thinking.

Teachers were administered the data collection instruments; Teacher Knowledge Survey, and Industry 4.0 and STEM Competencies Survey in three points in time; beginning of the project, end of Phase and end of Phase 4 [Table 2]. Teacher Perception Survey was administered only at the end of Phase 4. All data collection took place online through Google Forms.

\section{Industry 4.0 and STEM competencies survey}

A short survey of seven items was designed by the researchers to obtain information on teachers' reflections on their Industry

\section{Table 3: Teacher perceptions survey}

\section{Teacher perceptions survey questions}

1. What are some impacts of participation in this project concerning your professional development? Please focus on STEM education and Industry 4.0

2. How would you define your role as a teacher when you consider STEM education for technical and vocational high schools?

3. In what ways can STEM education impact and improve the goals of technical and vocational high schools?

4. How do you perceive the rich structure of courses; basic sciences (e.g., biology, physics, and mathematics) and technical courses at technical and vocational high schools concerning STEM and Industry 4.0?

5. What is the likelihood of a technical and vocational high school graduate student team to be assigned to a mission of sending a vehicle to Mars? Please explain your opinion. What possible role can you foresee for them?

6. How did participation in this project impact your school's culture? What are some changes that you observe?

7. What are the benefits and challenges of collaborating with your colleagues during this project?

4.0 competencies. Each item was developed to focus separately related to the Industry 4.0 components: robotic programming, mobile programming, and internet of things, 3D design, cloud computing, virtual reality, STEM lesson plan preparation, and STEM lesson plan implementation in classroom. It should be noted that the teachers were required to prepare the STEM lesson plans (a) following engineering design process steps (Massachusetts Department of Education, 2006), and (b) using Industry 4.0 components. Teachers' level of competence to use Industry 4.0 components effectively and to implement lesson plans that contained the components were revealed. Teachers responded to the items on a five-point Likert-type scale ranging from 1 (strongly disagree) to 5 (strongly agree) for a joint scale ranging from 7 to 35 points. All items had a similar structure exemplified by the following: "I feel competent in robotic programming," and "I feel competent in preparing lesson plans with Industry 4.0 components."

\section{Data Analysis}

Data collected with the Teacher Knowledge Survey were analyzed by categorizing teacher responses into distinct hierarchical knowledge levels. Table 4 outlines the final version of the levels used to evaluate teacher's content knowledge on STEM education and Industry 4.0. Following individual reading and creation of levels and their descriptions, the two researchers jointly discussed their suggestions for the levels. This process led to the final version of three knowledge levels: Poor, middle, and high together with their descriptions as seen in Table 4. Three knowledge levels were formed separately for STEM education and Industry 4.0. As the final step, the researchers assigned knowledge levels to teacher responses resulting in percentages for each level.

The qualitative data collected with the Teacher Perception Survey were examined by content analysis (Miles and Huberman, 1994). The researchers independently read teacher responses repeatedly which was then followed by creating list categories. Next, the researchers evaluated the category list together, making revisions 


\begin{tabular}{|c|c|c|c|c|}
\hline Content knowledge & Levels and descriptions & Baseline (\%) & End of Phase 2 (\%) & End of Phase 4 (\%) \\
\hline \multirow[t]{7}{*}{ STEM education } & $\begin{array}{l}\text { High; Collaboration of STEM disciplines to solve real life problems } \\
\text { and manufacture daily life products }\end{array}$ & 0 & 10 & 20 \\
\hline & Teacher Response: STEM education helps people & & & \\
\hline & $\begin{array}{l}\text { apply theoretical knowledge into real life products, creating solutions } \\
\text { for problems of society }\end{array}$ & & & \\
\hline & $\begin{array}{l}\text { Medium; Collaboration of STEM disciplines, positive outcomes of } \\
\text { disciplinary collaborations (e.g., application of knowledge, skills } \\
\text { development, design skills) }\end{array}$ & 10 & 35 & 35 \\
\hline & $\begin{array}{l}\text { Teacher response: STEM education integrates multiple disciplines the } \\
\text { goal is to transform theoretical knowledge into practice }\end{array}$ & & & \\
\hline & $\begin{array}{l}\text { Poor: Explicit form of STEM, or collaboration without necessarily } \\
\text { referring to STEM disciplines }\end{array}$ & 90 & 55 & 45 \\
\hline & $\begin{array}{l}\text { Teacher Response; Intersection and collaboration of science, } \\
\text { technology, engineering, and mathematics }\end{array}$ & & & \\
\hline \multirow[t]{6}{*}{ Industry 4.0} & $\begin{array}{l}\text { High; Communication of smart devices, Industry } 4.0 \text { components } \\
\text { (e.g., internet of things, big data, artificial intelligence), examples to } \\
\text { real-life situations (e.g., dark factories), prior industry revolutions }\end{array}$ & 0 & 15 & 39 \\
\hline & $\begin{array}{l}\text { Teacher Response: ... Industry } 4.0 \text { is bringing smart factories and } \\
\text { devices into our daily lives; smart robots are taking over humans' duties } \\
\text { changing usual mass production.......definitions of careers are changing }\end{array}$ & & & \\
\hline & $\begin{array}{l}\text { Medium; Communication of smart devices, Industry } 4.0 \text { components } \\
\text { (e.g., internet of things, virtual reality, 3D design) }\end{array}$ & 17 & 25 & 26 \\
\hline & $\begin{array}{l}\text { Teacher Response: all teachers must update themselves on Industry } \\
4.0 \text { components, ... internet of things affects our lives, dark factories.... }\end{array}$ & & & \\
\hline & $\begin{array}{l}\text { Poor; Use of technology, technological improvements, digitalization, } \\
\text { new career areas, economic improvement, school-industry cooperation }\end{array}$ & 83 & 60 & 35 \\
\hline & $\begin{array}{l}\text { Teacher Response: Production that is possible completely by } \\
\text { technological tools }\end{array}$ & & & \\
\hline
\end{tabular}

while removing the least common codes. Expressing differences of opinions resulted in the final category list. The concepts and phenomena that teachers frequently reported were revealed and reflected as categories (Miles and Huberman, 1994; Yıldırım and Şimşek, 2013). The unit of analysis was teacher responses; at times one sentence was assigned a category and at times a single paragraph. Table 5 presents the quantitative data analysis results. To examine the quantitative data collected with the Industry 4.0 and STEM Competencies Survey, a descriptive analysis was completed. The first step of preparing and organizing the data for analysis (Creswell, 2012) was scoring the data. For this step, the researchers assigned numeric values to the five response categories of the seven items. Teachers' responses ranging from 1 (strongly disagree) to 5 (strongly agree) made up of a possible individual item score between 1 and 5 and a total score between 7 and 35. Next, the researchers decided to use, use single-item scores for each response category, for three points in time; baseline, and of Phase 2 and end of Phase 4. The input data were then analyzed to reach percentages for the response categories of each of the seven items. Data analysis revealed the changes in teachers' preferences of the response categories for all items.

\section{RESULTS}

The results are presented in three sections based on the two research questions of the study. The first section presents findings on: (a) Teacher content knowledge on STEM and Industry 4.0 components; and (b) teacher perceptions related to STEM education and Industry 4.0. The second section illustrates the findings on teacher improvement on Industry 4.0 competencies and lesson plan preparation and implementation.

\section{Teacher Content Knowledge and Teacher Perceptions}

Teachers' level of content knowledge on STEM education and Industry 4.0 was investigated with the Teacher Knowledge Survey administered 3 times during the project. Table 4 highlights the results of the qualitative analysis with the percentages based on the identified levels: Poor, Middle, and High for STEM education and Industry 4.0 separately. The table also includes example teacher responses for each identified level.

Results demonstrated that for STEM education content knowledge, the percentage of teacher responses assigned to the knowledge level; high increased to a great extent; from $0 \%$ to $20 \%$ and from $0 \%$ to $39 \%$ for Industry 4.0 content knowledge. Likewise, for Industry 4.0 content knowledge, the percentage of teacher responses assigned to the knowledge level; Poor decreased significantly; from $90 \%$ to $45 \%$ for STEM education; and from $83 \%$ to $35 \%$. At the end of Phase 4 , the majority of teacher responses represented the category; high (39\%). A remarkable finding was that considering both STEM education and Industry 4.0 content knowledge indicators, at the end 


\begin{tabular}{|c|c|c|c|c|c|}
\hline $\begin{array}{l}\text { Industry } 4.0 \\
\text { components }\end{array}$ & $\begin{array}{c}\text { Strongly } \\
\text { disagree } \\
(\%)\end{array}$ & $\begin{array}{c}\text { Disagree } \\
\text { (\%) }\end{array}$ & $\begin{array}{l}\text { Undecided } \\
(\%)\end{array}$ & $\begin{array}{c}\text { Agree } \\
(\%)\end{array}$ & $\begin{array}{c}\text { Strongly } \\
\text { agree } \\
(\%)\end{array}$ \\
\hline \multicolumn{6}{|c|}{ Robotic programming } \\
\hline Baseline & 39.47 & 31.58 & 15.79 & 10.53 & 2.63 \\
\hline End of Phase 2 & 0.00 & 21.05 & 47.37 & 28.95 & 2.63 \\
\hline End of Phase 4 & 0.00 & 10.71 & 50.00 & 17.86 & 21.43 \\
\hline \multicolumn{6}{|c|}{ Mobile programming } \\
\hline Baseline & 50.00 & 21.05 & 26.32 & 2.63 & 0.00 \\
\hline End of Phase 2 & 5.26 & 31.58 & 47.37 & 10.53 & 5.26 \\
\hline End of Phase 4 & 0.00 & 17.86 & 42.86 & 25.00 & 14.29 \\
\hline \multicolumn{6}{|l|}{ 3D design } \\
\hline Baseline & 50.00 & 13.16 & 13.16 & 15.79 & 7.89 \\
\hline After Phase 2 & 2.63 & 7.89 & 39.47 & 34.21 & 15.79 \\
\hline End of Phase 4 & 0.00 & 7.14 & 32.14 & 25.00 & 35.71 \\
\hline \multicolumn{6}{|l|}{ Cloud computing } \\
\hline Baseline & 18.42 & 42.11 & 28.95 & 7.89 & 2.63 \\
\hline End of Phase 2 & 5.26 & 2.63 & 36.84 & 36.84 & 18.42 \\
\hline End of Phase 4 & 0.00 & 7.14 & 25.00 & 32.14 & 35.71 \\
\hline \multicolumn{6}{|c|}{ Virtual and Augment. Reality } \\
\hline Baseline & 18.42 & 42.11 & 28.95 & 7.89 & 2.63 \\
\hline End of Phase 2 & 2.63 & 18.42 & 55.26 & 21.05 & 2.63 \\
\hline End of Phase 4 & 0.00 & 7.14 & 53.57 & 25.00 & 14.29 \\
\hline \multicolumn{6}{|c|}{ STEM Lesson plan preparation } \\
\hline End of Phase 4 & 0.00 & 0.00 & 14.29 & 57.14 & 28.57 \\
\hline \multicolumn{6}{|c|}{ STEM Lesson plan implementation } \\
\hline End of Phase 4 & 0.00 & 0.00 & 10.71 & 25.00 & 64.29 \\
\hline
\end{tabular}

of Phase 4, a significant amount of teacher responses were categorized under poor: About $45 \%$ for STEM education and $35 \%$ for Industry 4.0 , respectively.

Teacher perceptions related to STEM education and Industry 4.0 as the teachers completed the teacher PD program was captured by Teacher Perception Survey. Results were presented under five categories persistently reported by the teachers: (a) Culture of collaboration, (b) increased motivation, (c) positive attitudes toward TVET, (d) a focus on practice, and (e) limitations faced.

One of the themes that came out frequently in teacher responses concerned a new culture of collaboration at school and their changed perceptions of their teacher colleagues. Teachers reported that they started to recognize their teacher colleagues at school as sources of knowledge and information for themselves. Three of the teachers indicated the following statements: "The project led to frequent communication and collaboration opportunities between all school staff, as teachers, students, and school administration....", "Being a part of this project, I recognized how this project served as a context for collaboration, helping teachers of different technical branches come together and work on new ideas...", and "I have observed a great improvement in the insufficiency of positive dialogue in our school with this project." The next category that summarized teacher perceptions; increased motivation supported the first category. Teachers expressed their views on how being a part of the project resulted in increased teacher and student motivation. One of the teachers emphasized this point with the response: "The project activities led to an increase in positive attitudes towards school and to increase in student and teacher motivation and excitement."

The next common category: Attitudes toward TVET were associated with the public perception of TVET high schools. It is evidenced that teachers perceived a change in positive public attitudes toward TVET education in general and TVET high schools. Two teachers demonstrated this idea with the following responses: "People in the school neighborhood expressed their interest to visit our school and find out more about the project. These visitor groups included teacher, students, and school administrators" and "We have observed an increase in positive attitudes from students and parents who regarding studying in TVET high schools." The teachers also highlighted the role of their involvement in the project in underlining a focus on practice. Teachers reported that they recognized the value of applying theoretical knowledge of $21^{\text {st }}$-century technologies, using their existing expertise in practice as part of technical education. The final most prevalent category: Limitations faced stressed some of the challenges teachers faced as they proceeded in the project. According to the results, teacher concerns pertained to three limitations related to available spaces to use for project tasks, rigid school schedules, and technical equipment. Two of the teachers underscored the role of strict weekly schedules in preventing them from completing the project tasks effectively: "Due to conflicts in programs and related time limitations, we had difficulty in reaching out to all teachers in our school...," "All project teachers were individually motivated to work on project tasks; however, time and available space limitations sometimes decreased their level of motivation." As a final point, the teachers reported their perceived need for a greater variety in the most up-to-date technical equipment, and an increase in the number of laboratories and other spaces in their school, for them to engage in new STEM projects.

\section{Teachers' Industry 4.0 Competencies}

Table 5 presents descriptive analysis results on Industry 4.0 and STEM Competencies Survey. The table outlines the percentages of teacher responses for each category (ranging from strongly disagree to strongly agree), separately for the three data collection points: Baseline, end of Phase 2, and end of Phase 4. As illustrated in Table 5, the results showed striking differences in how teachers perceived their competencies across the Industry 4.0 components: Robotic programming, mobile programming and internet of things, 3D design, cloud computing, and virtual and augmented reality. For STEM lesson plan preparation, and STEM lesson plan implementation in the classroom, teachers rated their competencies only at the end of Phase 4.

The results suggested that teachers showed improvement in their perceived competencies from the baseline to the end of Phase 4, for all Industry 4.0 components. This is evidenced by comparing the increase in percentages for the response 
categories; agree and strongly agree, and a decrease in the response categories; disagree and strongly disagree. Teachers are revealed to show the most improvement in the Industry 4.0 components: 3D design and Cloud Computing. For 3D design, percentages of the response category; strongly agree increased from $7.89 \%$ to $35.71 \%$, and for cloud computing, percentages of the response category; and strongly agree showed an increase from $2.63 \%$ to $35.71 \%$. For the Industry 4.0 components; robotic programming, mobile programming, and 3D design, the percentages of the response category; Strongly Disagree dramatically decreased, for example, from $50 \%$ to $0 \%$ for mobile programming, and $3 \mathrm{D}$ design. It is remarkable that for the two components; mobile programming and virtual reality and augmented reality, the percentage of teachers who did not mark Strongly Agree at the end of Phase 4 is considerably high; $85.71 \%$ for both components. Considering teachers' perceived competencies to prepare and implement a STEM lesson plan, results revealed a considerable percentage for the response category; undecided; $14.29 \%$ and $10.71 \%$ respectively. Although a great majority of the teachers (64\%) strongly agreed that they are competent in STEM lesson plan implementation, a smaller group of teachers (28\%) strongly agreed to their competency in STEM lesson plan preparation.

Results indicated that the teachers improved their Industry 4.0 competencies through the STEM PD Program; however, teachers still need to improve their competencies regarding robotic programming, mobile programming, virtual reality and augmented reality, and STEM lesson plan preparation.

\section{DISCUSSION}

The insights on training TVET teachers in Industry 4.0 and STEM education that can be gained by the study are two-fold: (a) an example model of a long-term teacher PD program specific to TVET teachers, and (b) comprehensive findings on teacher improvement from multiple aspects around STEM and Industry 4.0 including teachers' content knowledge, perceptions, and perceived competencies.

The improvement in teachers' STEM education content knowledge following teacher PD programs confirmed previous study findings (Holmlund et al., 2018; Ring et al., 2017). Teachers' conceptions of STEM education at the end of the project approximated the STEM education definitions by Moore et al. (2014) and The National Academy of Sciences (2014) that emphasized the integration of the four STEM disciplines into a particular design (e.g., lesson, unit) reflecting real-world issues. At the baseline, teachers had a conception of STEM education that did not necessarily point to interdisciplinary work. Rather the teachers were only aware of the importance of people collaborating and exchanging ideas. This conceptualization developed into a model that explained the integration of STEM disciplines to solve real-life problems still including engaging in teamwork. This revised conceptualization was in line with complex STEM education conceptualizations of teachers who participated in a teacher PD program in similar studies
(Aydin-Gunbatar et al., 2018; Ring et al., 2017). Teachers' conceptualizations also pointed to manufacturing products. This can be explained by the unique context of TVET high schools where technical products are produced. In support of this, engineering has been the dominant discipline in STEM education practices where production takes place (Martín-Páez et al., 2019). Designing a product was also mentioned by the STEM education conceptualizations of the teachers in AydinGunbatar et al. (2018)'s study. This complex conceptualization of STEM education could only be attained by less than half of the teachers at the end of the project. This finding addresses the need to improve TVET teachers' STEM education understanding regarding integration of all STEM disciplines in real-world challenges leading to solutions and/or products (Moore et al., 2014). In their comprehensive review of how STEM education is defined in the literature, Martín-Páez et al. (2019) also found out that using real-world problems to integrate all STEM disciplines is among the key aspects of STEM education.

The beginning of the project showed teacher conceptualizations of a naïve model where teachers showed awareness of technological and economical improvements, digitalization, and new career areas. Teachers' Industry 4.0 tools conceptualizations evolved into a comprehensive model that explained Industry 4.0 tools (e.g., virtual reality, augmented reality, and 3D printing), communication of smart devices, and real-life examples such as smart factories (Almeida and Simoes, 2019; Rojko, 2017).

Findings indicated that the teachers perceived improvement in their Industry 4.0 competencies for all the components, mostly for 3D design and cloud computing. Teachers perceived a less amount of improvement for the competencies, mobile programming, and virtual and augmented reality. These findings might suggest two things. First, the results can be associated with accessing the necessary equipment and spaces to use the components. It might have been the case that the teachers could access 3D printers and cloud computing tools more easily in their school contexts. Second, the teachers might have perceived using mobile programming and virtual and augmented reality in education to be more complex. In any case it is remarkable that teachers' perceived competencies would impact their use of the Industry 4.0 components in their lesson plans. It can be concluded that teachers will have more tendency to design lesson plans with 3D design and cloud computing and less with mobile programming and virtual and augmented reality. For students' success in their future worklife, familiarity with all Industry 4.0 components would be of priority (Chou et al., 2018; Lasi et al., 2014; Schleicher et al., 2019). It is critical to find out potential reasons for teachers' poor perceived competencies for some of the Industry 4.0 components and provide teachers more opportunities to practice classroom activities with components.

Teacher Perception Survey administered at the end of the project revealed that teachers perceived culture of collaboration in their schools. This confirmed similar studies that put forth 
the impact of STEM education practices in creating a positive school culture described by collaboration and sharing (ElDeghaidy and Mansour, 2015). Teachers at a school recognize the value of interaction, working together across different disciplines (El-Deghaidy and Mansour, 2015). Collaboration with peer teachers is among the contributors to the support teachers feel from their school to implement STEM education (Margot and Kettler, 2019). This is defined as school STEM culture by White et al. (2017) that combined school culture elements (e.g., beliefs, values, and practices) and STEM education. Teacher perceptions is one of the components of the culture of a school community (White et al., 2017). Positive teacher perceptions and attitudes is a critical factor for successful STEM education practices (Thibaut et al., 2018). This addresses the importance of STEM education programs in facilitating the increase in positive teacher perceptions and attitudes.

The impact of STEM education programs on increased teacher and student motivation and engagement is in line with the findings (Chittum et al., 2017; Nadelson et al., 2013). A striking finding was teachers' perceptions of the public's increased positive attitudes toward TVET education. This finding contributes to the need to prioritize the role of TVET education in society (Castellano et al., 2003). As TVET education meets the demand in adapting to STEM education practices (Fletcher and Gordon, 2017), TVET will continue to facilitate sustainable innovation in education practices (OECD, 2009). For sustainable development in education, recognition of TVET high schools should continuously be highlighted (Ayonmike and Okeke,, 2017; Fletcher and Tyson, 2017; OECD, 2019).

The participant teachers of our year-long STEM teacher PD program reported significant improvement in their knowledge, competencies, and perceptions. The results can serve as a justification for efforts towards designing programs for teachers to increase the potential of TVET education.

\section{CONCLUSIONS}

Because mathematics, science and technology content knowledge is used in TVET technical branches (Dixon and Hutton, 2016; Reeve, 2016), TVET high schools present an ideal educational context for innovative practices related to Industry 4.0 components and STEM education (Blosveren and Voytek, 2015; Dougherty and Macdonald, 2020; Reeve, 2016). This study illustrated that the STEM PD program contributed to TVET teachers' PD from multiple aspects. It was notable that the interaction and the collaboration between teachers advanced toward positive; as teachers of multiple teaching fields; teachers of basic sciences and teachers of technical branches formed a professional learning community. Teachers were given the opportunity to learn from each other as they engaged with the concepts and practices of multiple disciplines. The teachers acted together in the preparation and implementation of STEM lesson plans which contributed to teachers' positive perceptions and attitudes regarding STEM education. Teachers realized that a positive culture that emphasized collaboration and increased belongingness developed in their schools.

It can be said that the teachers' improved their content knowledge of STEM education and perceived themselves competent in implementing STEM lesson plans. Findings evidenced that the teachers could express what STEM disciplines are as well as the value of collaboration of multiple STEM disciplines however failed to put the focus on reallife problems and results of an interdisciplinary approach. Although teachers created STEM lesson plans based on real-life problems, it was observed that there are still areas of improvement in the statement that different disciplines cooperate to bring solutions to problems. While the teachers overall improved their Industry 4.0 competencies, the results suggested a need to do more work on mobile programming, robotic programming, virtual reality and augmented reality, and preparation of STEM lesson plans.

The teachers also reported limitations that prevented them from fully engaging in the project tasks stated that they had problems in finding the appropriate place and time to work collaboratively with their colleagues in the first applications. But afterward, they carried out effective works without using any difficulties with the development of the culture of working together and by using fast communication methods such as mobile applications from time to time. It is important that teachers realized the value of expertise of other teachers for their PD, because, thanks to this, they will also have developed a culture of mutual respect, positive communication, and learning together.

The year-long STEM teacher PD program designed in accordance with blended learning approach and the specific needs of TVET education contexts can serve as a model to similar program designs.

\section{Recommendations}

To further develop teachers' Industry 4.0 and STEM competencies, the total amount of time spared for face-to face training and online training can be increased to longer hours. More time devoted to the Industry 4.0 competencies; robotics programming, the Internet of things, virtual and augmented reality and mobile programming training can further develop the competencies of these components. Competencies to create STEM education lesson plan might be improved by addressing more exemplary practices and increased feedback during the training programs. It should be ensured that the knowledge and experience of the pedagogical concepts are increased. Special training can be organized for the development of the teachers to bring together the achievements related to different disciplines and to address them within the scope of a common subject or problem. This in fact suggests the need to stress the value of technical branch teachers in TVET education to be able to fully address Industry 4.0 components and engineering design process steps 
in STEM lesson plans. The factors: Curricular constraints and support from the school administration are stressed by the teachers as limitations. Teachers' curriculum should be prepared in harmony with each other to collaborate at school. For example, a curriculum can be prepared to make it easier for the mathematics teacher and the technical branch teacher who will take part in a STEM education study to be started in physics courses to carry out the process together. Overall, increased communication between schools and the industry might address these limitations.

\section{Limitations}

The results are limited to the data obtained before and after the year-long STEM teacher PD program. Follow-up interviews with the teachers and observations could have improved the validity of our results. All instruments revealed self-reported data, which might have led to limitations. Finally, the STEM lesson plans were not treated as data collections tools.

\section{ACKNOWLEDGMENTS}

This work is a product of the "STEM Education for Industry 4.0: Technical and Vocational High Schools" project funded by DOW. The project was implemented by Istanbul Aydin University STEM Education Research Center, upon the scope of the protocol signed between the Turkish Industry and Business Association (TUSIAD) and the Ministry of National Education of Turkey (MoNE).

\section{REFERENCES}

Akgunduz, D. (2016). A research about the placement of the top thousand students in STEM fields in Turkey between 2000 and 2014. Eurasia Journal of Mathematics Science and Technology Education, 12(5), 1365-1377.

Akgunduz, D. (Ed.) (2018). The Integration of STEM Education into the Curriculum. Istanbul Aydin University.

Akgunduz, D., \& Akınoğlu, O. (2016). The effect of blended learning and social media-supported learning on the students' attitude and selfdirected learning skills in science education. The Turkish Online Journal of Educational Technology, 15(2), 106-115.

Akgunduz, D., \& Akinoglu, O. (2017). The impact of blended learning and social media-supported learning on the academic success and motivation of the students in science education. Education and Science/Egitim ve Bilim, 42(191), 69-90.

Akgunduz, D., \& Mesutoglu, C. (2020). The STEM Education for the Industry 4.0: The Project and Data. TUSIAD.

Almeida, F., \& Simoes, J. (2019). The role of serious games, gamification and Industry 4.0 tools in the Education 4.0 paradigm. Contemporary Educational Technology, 10(2), 120-136.

Aydin-Gunbatar, S., Tarkin-Celikkiran, A., Kutucu, E.S., \& Ekiz-Kiran, B. (2018). The influence of a design-based elective STEM course on preservice chemistry teachers' content knowledge, STEM conceptions, and engineering views. Chemistry Education Research and Practice, 19(3), 954-972.

Ayonmike, C.S., \& Okeke, B.C. (2017). Improving technical vocational education for producing competent graduates in the $21^{\text {st }}$ century. International Journal of Vocational Education and Training, 24(1), 42-58.

Baran, E., Bilici, S.C., Mesutoglu, C., \& Ocak, C. (2019). The impact of an out-of-school STEM education program on students' attitudes toward STEM and STEM careers. School Science and Mathematics, 119(4), 223-235.

Blosveren, K., \& Voytek, S. (2015). STEM and CTE: A perfect match. Techniques: Connecting Education and Careers, 90(3), 20-23.
Bybee, R.W. (2018). STEM Education now more than ever. National Science Teachers Association Press.

Capraro, R.M., Capraro, M.M., Scheurich, J.J., Jones, M., Morgan, J., Huggins, K.S., Corlu, M.S., Younes, R., \& Han, S. (2016). Impact of sustained professional development in STEM on outcome measures in a diverse urban district. The Journal of Educational Research, 109(2), 181-196.

Castellano, M., Stringfield, S., \& Stone J.R. (2003). Secondary career and technical education and comprehensive school reform: Implications for research and practice. Review of Educational Research, 73(2), 231-272.

Castro, R. (2019). Blended learning in higher education: Trends and capabilities. Education and Information Technologies, 24(4), 25232546.

Chai, C.S. (2019). Teacher professional development for science, technology, engineering and mathematics (STEM) education: A review from the perspectives of technological pedagogical content (TPACK). The AsiaPacific Education Researcher, 28(1), 5-13.

Chang, S.H., Ku, A.C., Yu, L.C., Wu, T.C., \& Kuo, B.C. (2015). A science, technology, engineering and mathematics course with computer-assisted remedial learning system support for vocational high school students. Journal of Baltic Science Education, 14(5), 641-654.

Chittum, J.R., Jones, B.D., Akalin, S., \& Schram, Á.B. (2017). The effects of an afterschool STEM program on students' motivation and engagement. International Journal of STEM Education, 4(1), 1-16.

Choi, S.J., Jeong, J.C., \& Kim, S.N. (2019). Impact of vocational education and training on adult skills and employment: An applied multilevel analysis. International Journal of Educational Development, 66, 129138.

Chou, C.M., Shen, C.H., Hsiao, H.C., \& Shen, T.C. (2018). Industry 4.0 manpower and its teaching connotation in technical and vocational education. International Journal of Psychology and Educational Studies, 5(1), 9-14.

Cohen, L., Manion, L., \& Morrison, K. (2007). Research Methods in Education. Routledge.

Corlu, M.S., Capraro, R.M., \& Capraro, M.M. (2014). Introducing STEM education: Implications for educating our teachers in the age of innovation. Education and Science, 39(171), 74-85.

Creswell, J.W. (2012). Research Design: Qualitative, Quantitative and Mixed Methods Approaches. Sage Publications.

Dixon, R.A., \& Hutton, D.M. (2016). STEM and TVET in the Caribbean: A framework for integration at the primary, secondary, and tertiary levels. Caribbean Curriculum, 24, 1-26.

Dougherty, S.M., \& Macdonald, I.H. (2020). Can growth in the availability of STEM technical education improve equality in participation: Evidence from Massachusetts. Journal of Vocational Education and Training, 72(1), 47-70.

El-Deghaidy, H., \& Mansour, N. (2015). Science teachers' perceptions of STEM education: Possibilities and challenges. International Journal of Learning and Teaching, 1(1), 51-54.

Fletcher, E.C., \& Gordon, H.R. (2017). The status of career and technical education undergraduate and graduate programs in the United States. Peabody Journal of Education, 92(2), 236-253.

Fletcher, E.C., \& Tyson, W. (2017). Bridging technical skills gaps between high school students and local employers. Journal of Research in Technical Careers, 1(1), 20-31.

Gilchrist, A. (2016). Industry 4.0: The Industrial Internet of Things. Apress.

Gordon, H.R.D. (2008). The History and Growth of Career and Technical Education in America. ( $3^{\text {rd }}$ ed.). Waveland Press, Inc.

Hoeckel, K., \& Schwartz, R. (2010). Learning for Jobs OECD Reviews of Vocational Education and Training. Organisation for Economic Cooperation and Development.

Hoekstra, A., Kuntz, J., \& Newton, P. (2018). Professional learning of instructors in vocational and professional education. Professional Development in Education, 44(2), 237-253.

Holmlund, T.D., Lesseig, K., \& Slavit, D. (2018). Making sense of "STEM education" in K-12 contexts. International Journal of STEM Education, $5(32), 1-18$.

International Labour Organization. (2019). World Employment Social Outlook: Trends, 2019. International Labour Organization.

Johnson, C.C., Peters-Burton, E.E., \& Moore, T.J. (Eds.). (2015). STEM 
Road Map: A Framework for Integrated STEM Education. Routledge.

Jou, M., Hung, C.K., \& Lai, S.H. (2014). A comparative investigation on the learning efficacy of mechatronic technology between academic and vocational high school students. Journal of Science Education and Technology, 23(6), 777-783.

Lasi, H., Fettke, P., Kemper, H.G., Feld, T., \& Hoffmann, M. (2014). Industry 4.0. Business and Information Systems Engineering, 6(4), 239-242.

Margot, K.C., \& Kettler, T. (2019). Teachers' perception of STEM integration and education: A systematic literature review. International Journal of STEM Education, 6(2), 1-16.

Martín-Páez, T.,Aguilera, D., Perales-Palacios, F.J., \& Vílchez-González, J.M. (2019). What are we talking about when we talk about STEM education? A review of literature. Science Education, 103(4), 799-822.

Massachusetts Department of Education. (2006). Massachusetts Science and Technology/Engineering Curriculum Framework. Massachusetts Department of Education.

Miles, M.B., \& Huberman, A.M. (1994). Qualitative Data Analysis: A Sourcebook. Sage Publications.

Moore, T., Stohlmann, M., Wang, H., Tank, K., Glancy, A., \& Roehrig, G. (2014). Implementation and integration of engineering in K-12 STEM education. In: Purzer, S., Strobel, J., \& Cardella, M., (Eds.), Engineering in Pre-College Settings: Synthesizing Research, Policy, and Practices. pp. 35-60. Purdue University Press.

Nadelson, L.S., Callahan, J., Pyke, P., Hay, A., Dance, M., \& Pfiester, J. (2013). Teacher STEM perception and preparation: Inquiry-based STEM professional development for elementary teachers. The Journal of Educational Research, 106(2), 157-168.

National Academy of Sciences. (2014). STEM Integration in K12 Education: Status, Prospects, and an Agenda for Research. National Academies Press.

National Research Council. (2012). A Framework for K-12 Science Education: Practices, Crosscutting Concepts, and Core Ideas. National Academies Press.

National Research Council. (2014). Developing Assessments for the Next Generation Science Standards. National Academies Press.

Nilsson, A. (2010). Vocational education and training-an engine for economic growth and a vehicle for social inclusion? International Journal of Training and Development, 14(4), 251-272.

Oran, Y., Akgunduz, D., Adiguzel, Z., \& Altingovde, E. (2018). STEM education applications in vocational technical schools: Example of MOSTEM. Presented at the World STEM Education Conference - 8-10 June 2018.

Organisation for Economic Co-operation and Development. (2009). Working out Change: Systematic Innovation in Vocational Education and Training. OECD Publishing.

Organisation for Economic Co-operation and Development. (2019). How's Life in the Digital Age: Opportunities and Risks of the Digital Transformation for People's Well-being. OECD Publishing.

Reeve, E.M. (2016). $21^{\text {st }}$ century skills needed by students in technical and vocational education and training (TVET). Asian International Journal of Social Sciences, 16(4), 65-82.

Ring, E.A., Dare, E.A., Crotty, E.A., \& Roehrig, G.H. (2017). The evolution of teacher conceptions of STEM education throughout an intensive professional development experience. Journal of Science Teacher Education, 28(5), 444-467.

Rojko, A. (2017). Industry 4.0 concept: Background and overview. International Journal of Interactive Mobile Technologies, 11(5), 77-90.

Schleicher, A., Achiron, M., Burns, T., Davis, C., Tessier, R., \& Chambers, N. (2019). Envisioning the Future of Education and Jobs: Trends, Data and Drawings. OECD Publishing.
Shahali, E.H.M., Halim, L., Rasul, M.S., Osman, K., \& Zulkifeli, M.A (2017). STEM learning through engineering design: Impact on middle secondary students' interest towards STEM. Eurasia Journal of Mathematics, Science and Technology Education, 13(5), 1189-1211.

Shernoff, D.J., Sinha, S., Bressler, D.M., \& Ginsburg, L. (2017). Assessing teacher education and professional development needs for the implementation of integrated approaches to STEM education. International Journal of Stem Education, 4(13), 1-16.

Siemens, G., Gašević, D., \& Dawson, S. (2015). Preparing for the Digital University: A Review of the History and Current State of Distance, Blended and Online Learning. Athabasca University Press.

Simonson, M., Smaldino, S., Albright, M., \& Zvacek, S. (2014). Teaching and Learning at a Distance: Foundations of Distance Education. ( $6^{\text {th }}$ ed.). Allyn and Bacon.

The United Nation Educational Scientific and Cultural Organization. (2004). Normative Instruments Concerning Technical and Vocational Education. UNESCO.

Thibaut, L., Ceuppens, S., De Loof, H., De Meester, J., Goovaerts, L., Struyf, A., Pauw, J.B., Dehaene, W., Deprez, J., De Cock, M. Hellinckx, L., Knipprath, H., Langie, G., Struyyen, K., Van de Velde, D., Van Petegem, P., \& Depaepe, F. (2018). Integrated STEM education: A systematic review of instructional practices in secondary education. European Journal of Stem Education, 3(1), 1-12.

Thibaut, L., Knipprath, H., Dehaene, W., \& Depaepe, F. (2018). The influence of teachers' attitudes and school context on instructional practices in integrated STEM education. Teaching and Teacher Education, 71, 190205.

Tripney, J.S., \& Hombrados, J.G. (2013). Technical and vocational education and training (TVET) for young people in low-and middle-income countries: A systematic review and meta-analysis. Empirical Research in Vocational Education and Training, 5(3), 1-14.

Uzmanoglu, S., İşgören, N.Ç., Çınar, A., Tektaş, N., Oral, B., Büyükpehlivan, G., \& Polat, Z. (2010). Evaluation of educational and technical structure at vocational schools. Procedia-Social and Behavioral Sciences, 2(2), 3447-3451.

Vennix, J., Den Brok, P., \& Taconis, R. (2017). Perceptions of STEMbased outreach learning activities in secondary education. Learning Environments Research, 20(1), 21-46.

Watters, J.J., \& Christensen, C. (2014) Vocational education in science, technology, engineering and maths (STEM): Curriculum innovation through school industry partnerships. In C. P. Constantinou, N. Papadouris, \& A. Hadjigeorgiou (Eds.), E-Book Proceedings of the ESERA, 2013 Conference: Science Education Research for Evidencebased Teaching and Coherence in Learning. pp. 89-110. Nicosia, Cyprus. European Science Education Research Association.

White, C., Marshall, J.C., \& Alston, D. (2019), Empirically supporting school STEM culture the creation and validation of the STEM Culture Assessment Tool (STEM-CAT). School Science and Mathematics, 119(6), 299-311.

Wilkin, T., \& Welty, G.A. (2014). The qualification process for career/ technical education (cte) teachers: A new conceptual model. Journal of Education and Human Development, 3(2), 21-36.

Wu, M.C., Marsono, M., \& Khasanah, F. (2019). Advancing Vocational Student's Self-Efficacy through Integration STEM (Science Technology Engineering and Mathematics) Education. In: $2^{\text {nd }}$ International Conference on Vocational Education and Training (ICOVET, 2018). Atlantis Press.

Yıldırım, A., \& Şimşek, H. (2013). Qualitative Research Methods in the Social Sciences. Turkey: Seckin Publishing House.

Yin, R.K. (2008). Case Study Research: Design and Methods. Sage. 